\title{
Erbium oxide as a new promising tritium permeation barrier
}

\author{
D. Levchuk ${ }^{1}$, S. Levchuk ${ }^{1}$, H. Maier ${ }^{1}$, H. Bolt ${ }^{1}$, A. Suzuki ${ }^{2}$ \\ ${ }^{1}$ Max-Planck-Institut für Plasmaphysik, EURATOM Association, Garching, Germany \\ ${ }^{2}$ Nuclear Engineering Research Laboratory, Univ. of Tokyo, Japan
}

\section{Introduction}

Among several approaches to controlling tritium permeation and accumulation in the first wall of a fusion reactor, the application of a permeation barrier in the form of a coating looks feasible. In spite of decades spent in looking for an appropriate barrier material, there is still no universally recognised one, although alumina is most regarded among these coatings [1-4] since a few microns of a crystalline $\alpha$-alumina layer is capable of reducing the permeability a fusion relevant material, e.g. EUROFER 97, up to a factor of $10^{3}$ or greater [5]. However, crystalline alumina suffers from advanced requirements for its formation [6, 7].

One of the main parameters of a diffusion barrier is a so-called permeation reduction factor (PRF), i.e. the ratio of permeabilities or permeation fluxes through the uncoated sample to that of the coated one. Therefore, it is worth searching for a suitable material based on its permeation properties first and then exploring how the coating fits the other requirements. A decision was made to investigate erbia coatings, not only based on permeability but also on mechanical stability under thermal load when erbia is in contact with other materials. The choice of erbia was governed by our experience in deposition of crystalline erbia coatings [8], its compatibility with liquid Li $[9,10]$, and stability of its insulating properties upon neutron irradiation [11].

Here, we present the results of investigation of a three-layer sample EUROFER-Er ${ }_{2} \mathrm{O}_{3}$ $\mathrm{C}$ subjected to temperatures as high as $750^{\circ} \mathrm{C}$. The graphite substrate was used because of its low atomic number that allowed the application of IBA (Ion Beam Analysis) to reveal thermal stability of the layers and diffusion processes between erbia and EUROFER. With a heavier substrate, the signals of erbium, oxygen and EUROFER constituents would be hidden on IBA spectra.

Measurements on deuterium permeability through a Pd-30\% Ag and EUROFER 97 membranes coated with a one micron thick crystalline erbia layer are also reported. The Pd$30 \% \mathrm{Ag}$ substrate was used as a laboratory test substrate because it has high hydrogen 
permeability as well as resistance to oxidation and thus has little effect on hydrogen transport through the coated sample.

\section{Experimental details}

\section{Sample preparation}

Preparation of the $\mathrm{Er}_{2} \mathrm{O}_{3}-\mathrm{Pd}-30 \% \mathrm{Ag}$ and $\mathrm{Er}_{2} \mathrm{O}_{3}$-EUROFER samples was similar to that described in [8]: a polished disk-shaped substrate of $20 \mathrm{~mm}$ in diameter and $0.15 \mathrm{~mm}(\mathrm{Pd}-$ $30 \% \mathrm{Ag}$ ) or $0.36 \mathrm{~mm}$ (EUROFER) in thickness was coated with a $1 \mu \mathrm{m}$ erbia layer using a filtered arc deposition device. Deposition was performed by running an arc discharge on an erbium cathode, filtering plasma from metal droplets and introducing oxygen into the main chamber. The coating was deposited on the substrate at a temperature of $600^{\circ} \mathrm{C}$ to build up the dense crystalline erbia phase. The quality of the coating was then examined with SEM (Scanning Electron Microscopy) and XRD (X-Ray Diffraction) techniques. Since the sample was continuously exposed to oxygen during deposition, the back side of the EUROFER substrate was found to be strongly oxidised. To remove this oxide layer, an argon glow discharge was applied to that side after the coating had been formed.

For coating a graphite substrate with an erbium oxide layer and a EUROFER layer, both $500 \mathrm{~nm}$ in thickness, two PVD techniques were used: the filtered arc and magnetron devices. The parameters and procedure of erbia deposition were similar to those described above, except for application of an RF bias voltage of $-100 \mathrm{~V}$ to the substrate and lack of the back side etching. Sputter deposition of EUROFER on the deposited erbia layer was carried out by utilising a EUROFER 97 cathode. The deposition parameters were optimised to achieve appropriate characteristics of the depositing EUROFER layer, e.g. proper composition, uniformity of the depositing layer etc.

\section{Experimental technique}

The experimental facility and procedure used for permeation tests were described in detail in [5]. A membrane sealed with two gold O-rings divided the device in two parts, the high-pressure volume (HPV) and the low-pressure volume (LPV), and was heated by means of an electric furnace. Deuterium was introduced into the HPV through a liquid nitrogen trap to reduce water contamination in the incoming gas. Detection of the permeated gas was carried out by a quadruple mass-spectrometer working in the dynamic regime of measurements when the LPV is continuously pumped. Base pressures in the LPV and the 
HPV were $10^{-7}$ and $10^{-6} \mathrm{~Pa}$, respectively. The deuterium pressure in the HPV was increased stepwise; the next portion was added when a steady-state level of permeation rate had been achieved. After each experimental run, the sample, installed with the coating directed towards the HPV, was annealed at $750^{\circ} \mathrm{C}$ to release deuterium accumulated in the bulk.

To investigate the behaviour of the deposited samples under heat load, annealing at $750^{\circ} \mathrm{C}$ (heating rate of $20 \mathrm{~K} / \mathrm{min}$ ) was performed in a high vacuum annealing apparatus. The total working pressure during heating and annealing was controlled to be (2-9) $10^{-4} \mathrm{~Pa}$, the duration was $2 \mathrm{~h}$. Permeation tests were also a kind of heat load, since the samples underwent numerous cycles of heating and cooling within several months.

A number of analysis techniques were utilised to characterise the samples before and after experiments, namely SEM, XRD, and IBA.

\section{Results}

\section{EUROFER-Er $\mathrm{O}_{3}-\mathrm{C}$ sample}

In Fig. 1, SEM images of the as-deposited and annealed samples are shown. It is seen that annealing resulted in some changes owing to either appearance of erbium on the surface (erbium diffusion through the EUROFER layer or cracking of the top layer) or increasing the surface roughness. Erbium has a high atomic number of 68, and using backscattered electrons (BSE) mode would have revealed the presence of erbium on the surface as this mode is sensitive to atomic number. However, we did not observe rise of the image contrast in the BSE mode. Therefore, the difference in the SEM images was explained by increased roughness of one or both the layers.

The composition of the layers was investigated by IBA before and after annealing and no change in composition of both the layers was found. Additionally, comparison of the IBA spectra acquired before and after annealing confirmed that only roughness of the EUROFER layer rose upon annealing, in agreement with the SEM results.

The results of XRD analysis of the original and annealed samples are presented in Fig. 2. The solid curve is for the original sample, while the dashed one is the annealed. They both showed the same XRD pattern without any noticeable difference and revealed four peaks corresponding to $\mathrm{Er}_{2} \mathrm{O}_{3}$, namely (222), (400), (440), and (622), and one peak of $\mathrm{Fe}-\mathrm{Cr}$ (110) corresponding to the EUROFER layer. In other words, the layers kept their structures and no new phase was formed. 


\section{$\mathrm{Er}_{2} \mathrm{O}_{3}-\mathrm{Pd}-30 \% \mathrm{Ag}$ and $\mathrm{Er}_{2} \mathrm{O}_{3}$-EUROFER samples}

The permeation flux through the $\mathrm{Er}_{2} \mathrm{O}_{3}-\mathrm{Pd}-30 \% \mathrm{Ag}$ sample as a function of applied pressure is given in Fig. 3 for three values of temperature. In addition, the solid line represents the flux through the uncoated $\mathrm{Pd}-30 \% \mathrm{Ag}$ sample at the highest temperature used in the experiments. After the experiments, no surface cracks were observed. The values of permeability at certain pressures and temperatures were reproducible. The permeation flux $J$ was well fitted by the following function of the applied deuterium pressure $p$ :

$$
J=p^{0.6} \text {. }
$$

Assuming deuterium transport in erbia in the form of atoms, an exponential factor of 0.5 would correspond to the diffusion limited regime of permeability, while a value of 1 would indicate a surface limited one. Here, the regime of permeability was mixed but close to diffusion limited.

A typical permeation flux through the $\mathrm{Er}_{2} \mathrm{O}_{3}$-EUROFER sample vs. applied pressure curve is given in Fig. 4 for $600^{\circ} \mathrm{C}$ to show the quality of steady-state level at each applied pressure. Similar data were acquired for temperatures ranging from 400 to $700^{\circ} \mathrm{C}$. As seen from Fig. 4, a steady-state value of permeability was achieved at each pressure step. As in the previous case, the values of permeation flux were found to be reproducible.

For comparison, values of PRF for erbia deposited on the two mentioned substrates as well as for alumina deposited on EUROFER 97 from [5] are given in Table 1, along with the deposition parameters.

\section{Discussion}

The data on erbia is limited and it was hard to predict the interaction processes which could occur between substrate and coating and potentially affect the hydrogen permeability.

After annealing of the EUROFER- $\mathrm{Er}_{2} \mathrm{O}_{3}-\mathrm{C}$ sample, the crystals were grown on the surface of the EUROFER layer which resulted in an increase of the layer roughness. In spite of that, the surface of the sample was homogeneously covered by the steel without any open areas. Furthermore, no new phase appeared nor was any interaction between erbia and EUROFER. Interdiffusion between the erbia (in case of erbium excess in the deposited layer) and the EUROFER layer was not observed. In addition, no carbon permeated through the erbia layer upon annealing.

Concerning the performance of erbia as a diffusion barrier, it is found to be comparable to that of $\alpha$-alumina (see Table 1). Erbia, however, requires less effort to form a dense 
crystalline coating. From the experiments, we found that the regime of deuterium permeation through the sample coated with a $1 \mu \mathrm{m}$ thick erbia layer is close to diffusion limited. Thus, one can expect that in complex systems, where a barrier coating is surrounded with other materials, erbia will suppress permeability almost as efficiently as it does in our experiments because its performance is mostly governed by slow hydrogen transport through the bulk rather than by surface effects such as adsorption and recombination.

Erbia on EUROFER showed better performance than being deposited on Pd-30\% Ag. The reason for that has not been investigated yet and needs to be clarified. However, one can suspect that pre-oxidation of the EUROFER surface, i.e. formation a thin $\mathrm{Cr}_{2} \mathrm{O}_{3}$ layer helps erbia crystallites nucleating closer to the substrate resulting in a more dense structure. Similar effect was observed during deposition of $\alpha$-alumina on $\mathrm{Cr}$ containing films in [7]: $\mathrm{Cr}$ oxidised and the oxide served as a catalyst for nucleation of the depositing alumina coating.

Erbia markedly suppresses hydrogen transport and shows thermal stability and compatibility with some materials. The fact that erbia does not reveal any phase transformation at temperatures up to $2300^{\circ} \mathrm{C}$ [12], is stable with respect to liquid $\mathrm{Li}$, and keeps its electrical properties upon neutron irradiation makes it a possible candidate for hydrogen barrier coatings. There are still open questions though, regarding, for instance, neutron irradiation effects on the barrier properties, as well as erbia compatibility with PbLi.

\section{Conclusion}

Experiments with a crystalline erbia coating have been carried out to reveal its applicability as a hydrogen permeation barrier. It is found that erbia is compatible with several materials demonstrating no imperfections after being subjected to thermal loading at temperatures as high as $750^{\circ} \mathrm{C}$. Erbia efficiently suppresses hydrogen transport, mostly due to deceleration of diffusion rather than inhibiting surface processes. We are currently exploring other methods of deposition of erbia to make this coating feasible for fusion applications.

\section{Acknowledgements}

This work has been performed within the framework of the Integrated European Project "ExtreMat" (contract NMP-CT-2004-500253) with financial support by the European Community. It only reflects the view of the authors and the European Community is not liable for any use of the information contained therein. 


\section{References}

1. K. Verghese, L.R. Zumwalt, C.P. Feng, T.S. Elleman, J. Nucl. Mater. $85 \& 86$ (1979) 1161-1164

2. K.S. Forcey, D.K. Ross, C.H. Wu, J. Nucl. Mater. 182 (1991) 36-51

3. R.G. Song, Surf. Coat. Technol., 168 (2003) 191-194

4. G.W. Hollenberg, E.P. Simonen, G. Kalinin, A. Terlain, Fusion Eng. Des. 28 (1995) 190208

5. D. Levchuk, F. Koch, H. Maier, H. Bolt, J. Nucl. Mater. 328 (2004) 103-106

6. R. Brill, F. Koch, J. Mazurelle, D. Levchuk, M. Balden, Y. Yamada-Takamura, H. Maier, H. Bolt, Surf. Coat. Technol., 174-175 (2003) 606-610

7. T. Kohara, H. Tamagaki, Y. Ikari, H. Fujii, Surf. Coat. Technol. 185 (2004) 166-171

8. F. Koch, R. Brill, H. Maier, D. Levchuk, A. Suzuki, T. Muroga, H. Bolt, J. Nucl. Mater. 329-333 (2004) 1403-1406

9. B.A. Pint, P.F. Tortorelli, A. Jankowski, J. Hayes, T. Muroga, A. Suzuki, O.I. Yeliseyeva, V.M. Chenov, J. Nucl. Mater. 329-333 (2004) 119-124

10. B.A. Pint, J.H. De Van, and J.R. DiStefano, J. Nucl. Mater. 307-311 (2002) 1344-1350

11. T. Tanaka, A. Suzuki, T. Muroga, F. Sato, T. Iida, T. Nishitani, J. Nucl. Mater. 329-333 (2004) 1434-1437

12. ICDD powder diffraction file data base, version 2.1, June 2000 
Table 1 Parameters of deposition and performance of $1 \mu \mathrm{m}$ thick alumina [5] and erbia coatings

\begin{tabular}{|c|c|c|c|c|}
\hline Sample & $\begin{array}{c}\text { Temperature of } \\
\text { deposition }\end{array}$ & Bias voltage & $\begin{array}{c}\text { Temperature } \\
\text { range tested }\end{array}$ & $\begin{array}{c}\text { Mean value of } \\
\text { PRF }\end{array}$ \\
\hline $\begin{array}{c}\mathrm{Er}_{2} \mathrm{O}_{3^{-}} \\
\mathrm{Pd}-30 \% \mathrm{Ag}\end{array}$ & $600^{\circ} \mathrm{C}$ & no & $300-500^{\circ} \mathrm{C}$ & 300 \\
\hline $\begin{array}{c}\mathrm{Er}_{2} \mathrm{O}_{3^{-}} \\
\mathrm{EUROFER}\end{array}$ & $600^{\circ} \mathrm{C}$ & no & $400-700^{\circ} \mathrm{C}$ & 800 \\
\hline $\begin{array}{c}\alpha-\mathrm{Al}{ }_{2} \mathrm{O}_{3^{-}} \\
\mathrm{EUROFER}\end{array}$ & $730^{\circ} \mathrm{C}$ & $-200 \mathrm{~V}$ & $600-800^{\circ} \mathrm{C}$ & 1000 \\
\hline
\end{tabular}




\section{Figure captions}

Fig. 1 SEM images of the EUROFER-Er $\mathrm{O}_{2} \mathrm{O}_{3}-\mathrm{C}$ sample before (left) and after (right) annealing for $2 \mathrm{~h}$ at $750^{\circ} \mathrm{C}$

Fig. 2 XRD spectra of the EUROFER-Er $\mathrm{O}_{3}-\mathrm{C}$ sample before (solid) and after (dashed) annealing for $2 \mathrm{~h}$ at $750^{\circ} \mathrm{C}$

Fig. 3 Deuterium permeation flux vs. applied pressure dependence for the $\mathrm{Er}_{2} \mathrm{O}_{3}-\mathrm{Pd}-30 \% \mathrm{Ag}$ sample

Fig. 4 Dependence of deuterium permeation flux through the $\mathrm{Er}_{2} \mathrm{O}_{3}-\mathrm{EUROFER}$ sample on time with stepwise increases of applied pressure at $600^{\circ} \mathrm{C}$. 

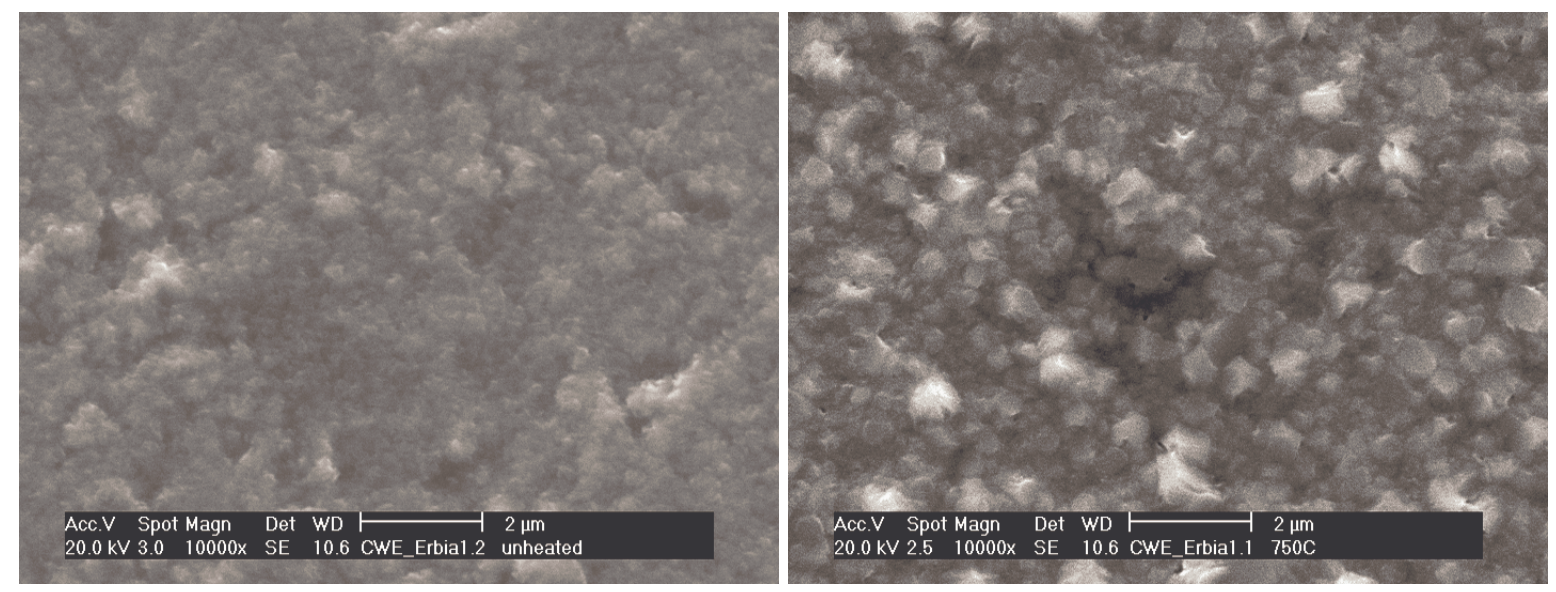

Fig. 1 SEM images of the EUROFER-Er $\mathrm{O}_{2}-\mathrm{C}$ sample before (left) and after (right) annealing for $2 \mathrm{~h}$ at $750^{\circ} \mathrm{C}$ 


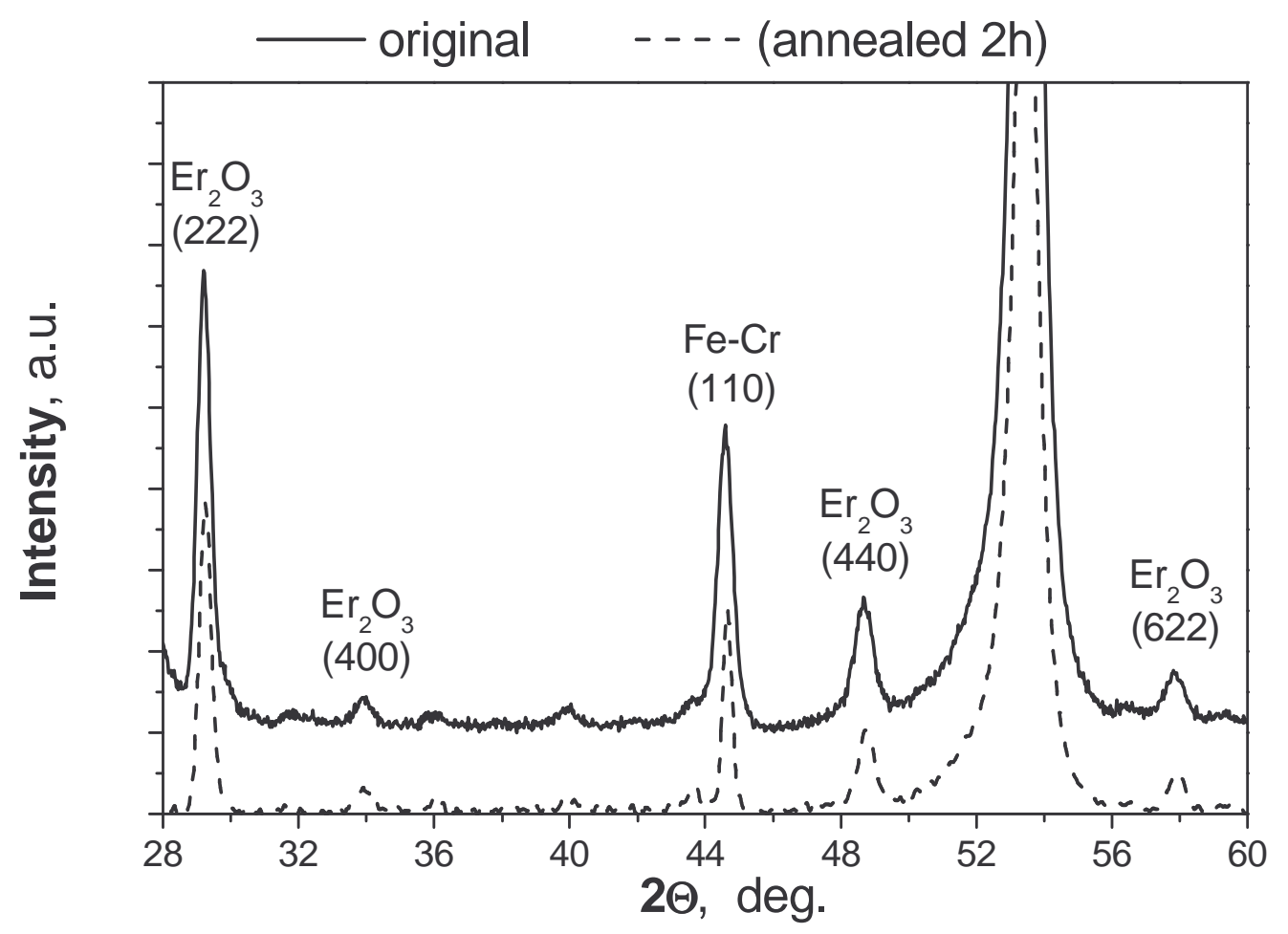

Fig. 2 XRD spectra of the EUROFER-Er ${ }_{2} \mathrm{O}_{3}-\mathrm{C}$ sample before (solid) and after (dashed) annealing for $2 \mathrm{~h}$ at $750^{\circ} \mathrm{C}$ 


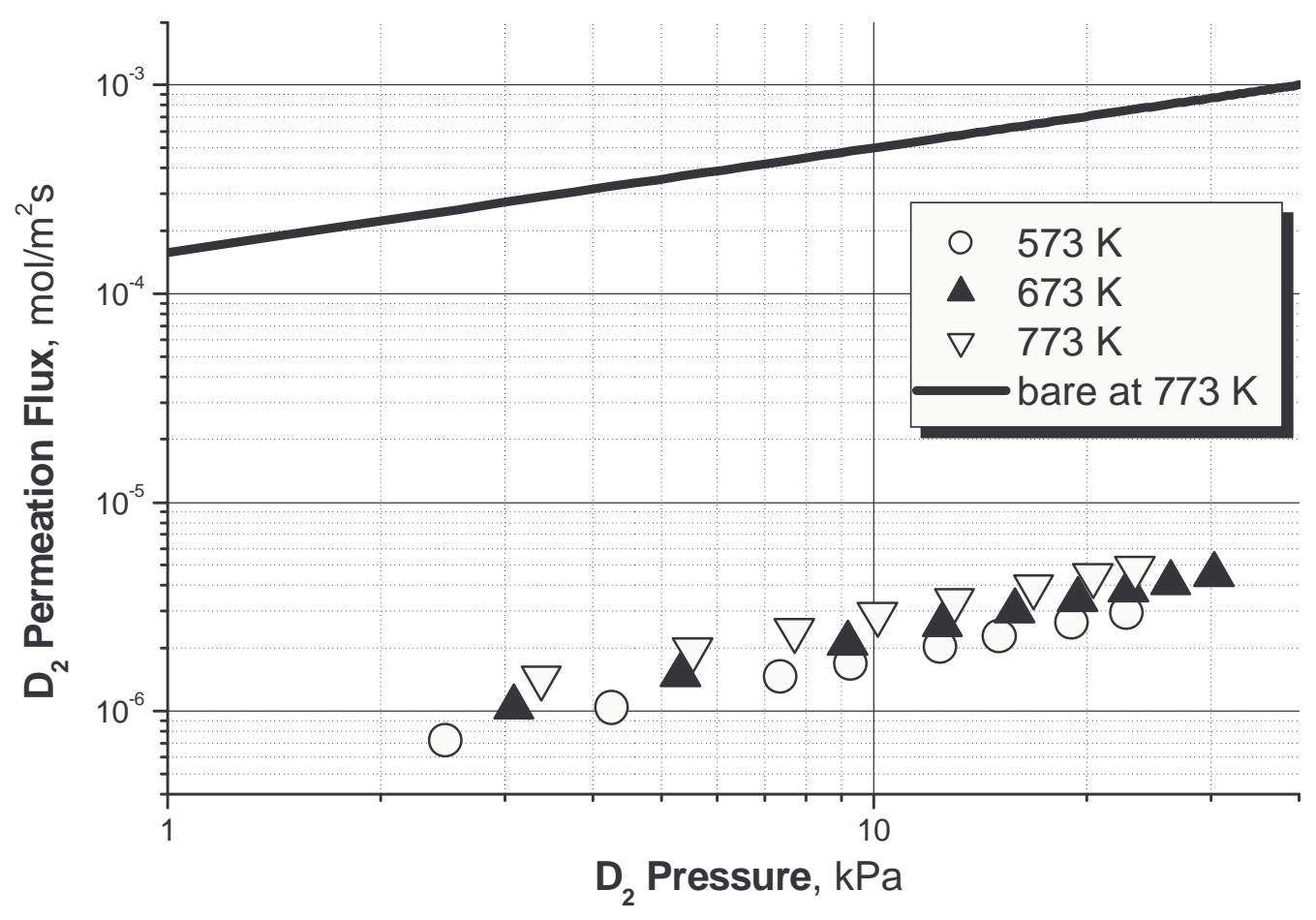

Fig. 3 Deuterium permeation flux vs. applied pressure dependence for the $\mathrm{Er}_{2} \mathrm{O}_{3}-\mathrm{Pd}-30 \% \mathrm{Ag}$ sample 


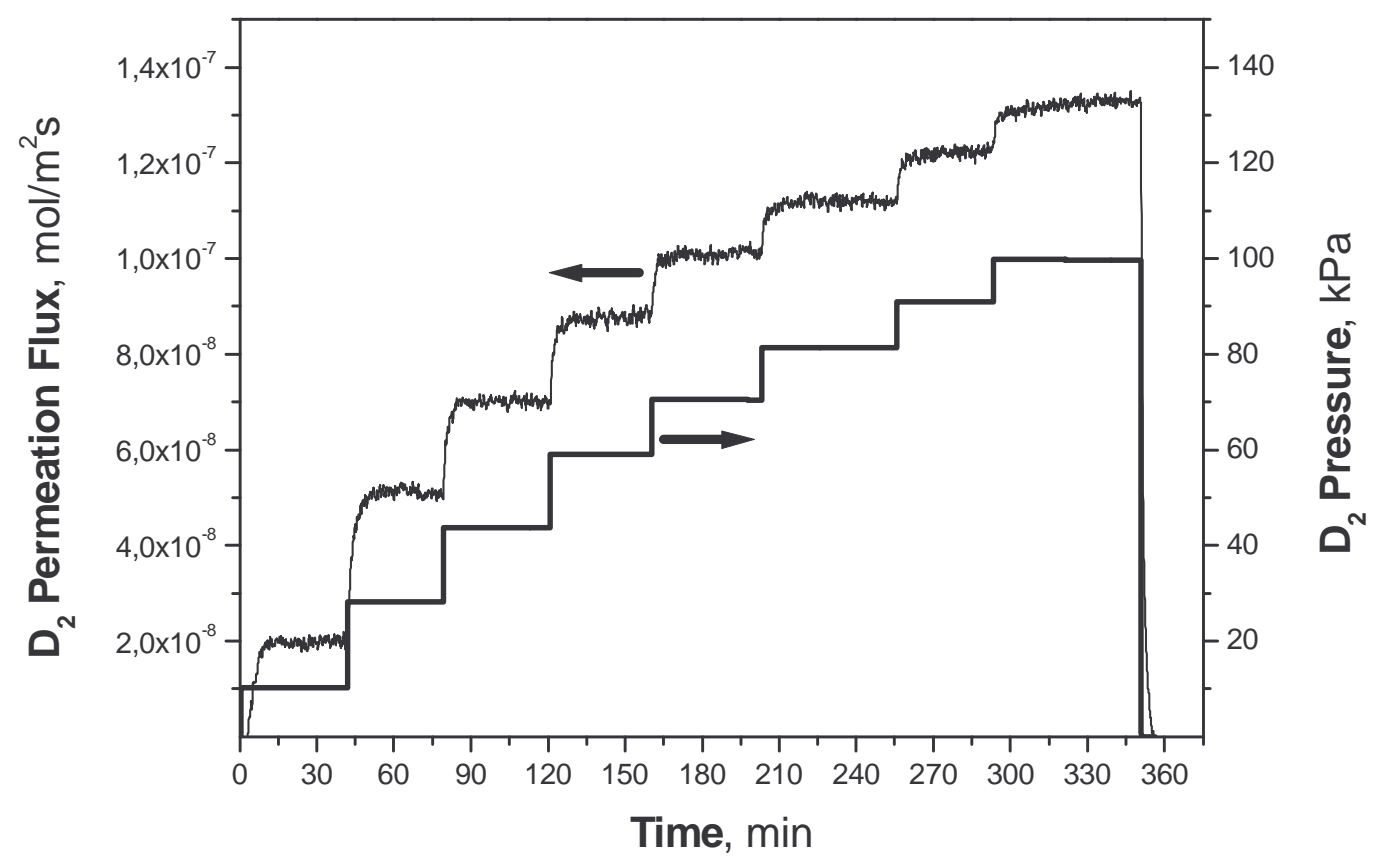

Fig. 4 Dependence of deuterium permeation flux through the $\mathrm{Er}_{2} \mathrm{O}_{3}$-EUROFER sample on time with stepwise increases of applied pressure at $600^{\circ} \mathrm{C}$ 